\title{
Public involvement in sustainable development: a public participation process in the Sidi Gaber railway station development project, Alexandria, Egypt
}

\author{
S. S. A. Aly \& M. S. E. Amer \\ Arab Academy for Science, Technology and Maritime Transport, \\ Architectural Engineering and Environmental Design Department, Egypt
}

\begin{abstract}
Public Participation (PP) in sustainable development helps the decision makers to acquire information about the public's preferences. So it plays a vital role in the decisions about choice of projects and formulates its design policies. PP is designed to help assure that the people's will is done; it gives the opportunity for people to be heard and to understand what will be done in a specific project. On a legality side, PP gives legitimacy for decisions, support for plans and builds trust in government.

A vested interest in PP had grown in Egypt and in most other developed countries, the public became much more concerned about participation and involvement in governmental decision making processes than they had been before. For that, the confidence between the public and decision makers has increased.

This paper aims to design the PP process for the Sidi Gaber railway station development project, Alexandria, Egypt. It will discuss the methods of PP practice and highlights the importance of the participation process in fulfilling people's needs and requirements, it explains the benefits that will be gained in the future by enriching environmental democracy.

The paper concludes that stakeholders do have influence over decisions and the government should have the ability to manage the conflicts, to deal with anger and aggressive behaviour and to gain the public trust instead of mistrust by ignoring PP. Sidi Gaber station has a special location, a unique architectural style and a historical value; so the research carried on a questionnaire to know the
\end{abstract}


public opinion about this project especially from the logic of heritage rehabilitation and maintenance, and from the environmental point of view.

Keywords: public participation, public involvement, sustainable development.

\section{Introduction}

In the last few years, public participation (PP) has taken the center of concern by playing a vital role that makes citizens participate in managing and protecting environment (Beierle and Cayford [1]). PP is a social process, so a great effort should be done to guide citizens how to participate, another effort to highlight the importance of participation process and its aim to fulfil their requirements. Thus, the process needs a lot of time for implementation and cooperation of people with the decision makers. Although it may be a difficult process to be implemented, a lot of benefits will be gained in the future by enriching democracy when people see their communities as they want. PP will show stakeholders that they do have an influence over the decisions taken and how governments will use their abilities to manage the conflicts (Raimond [2]). The participation process can become a guidance tool for civilization and integral life in Egypt; it will consummate the success of any development project, and vice versa, that is the focal point in this research. The study will discuss the ignorance of PP in the Sidi Gaber railway station development project, although that station has a special location and historical value; and was rather making a questionnaire to know the public opinion about this project.

Sidi Gaber railway station building has a unique architectural style; its building characterized by striping rows of yellow thermal bricks. Historically, the majority of Egyptian presidents had passed by it, so it has a grandiose history which is owned to all citizens (Asharq Al-Awsat newspaper [3]). Most of the stakeholders in this case will be public people such as occupants, train passengers, architects, and interested people. Those people may have anger reaction towards any conflicting decision with their personal desires and aspirations.

Thus, the participation process should include various cultures and intents. This study will guide people how to participate in such a process, it will emphasise the "social goals" in a well functioning environmental management system. The considered aims are: (1) Encourage public to participate and guiding them to the way of participation; (2) Increasing the substantive quality of decisions; (3) Incorporating public values into decision-making; (4) Increasing the awareness of the governmental officials, businesses and NGOs regarding public participation in environmental decision-making; (5) Rebuilding trust in government agencies; (6) suggesting and implementing the public participation in Egypt.

\subsection{The research methodology}

The research begins with outlining the process of PP, its theories and practices. Then discussing PP in the field of urban development; identifying the actions of 
intervention in a societal context relative to community needs and involvement. The importance of PP comes through the examples of public involvement in the project of Stuttgart Railway station, it intended to test the principles of participation through the management practice. Identifying various successful approaches will set the guidelines of applying such process nationally and offering environmental democracy in Egypt.

\subsection{Purpose of public participation}

A number of purposes have been advanced for public participation in planning and policy decision making. One is simply for decision makers to acquire information about the public's preferences so they can participate in the decisions taken in projects, policies or plans. The main purpose of PP is to assure that the people's will is done (Innes and Booher [4]). Another purpose is to improve the decisions taken by incorporating the knowledge of the public or members of the public into the calculus of the decision. Thus, public are more aware about the traffic jams or crime problems on a particular street, and the planners and decision makers can learn about this through public involvement. These purposes are increasingly important as government gets larger and more impersonal and more distant from its constituencies. PP is also about fairness and justice. There are systematic reasons why the least advantaged groups' needs and preferences are likely to be unrecognized through the normal analytic procedures and information sources of bureaucrats, legislative officials and planners. These needs may only be appeared when an opening of PP process occurs, so PP gives the opportunity for people to be heard who were misunderstood in the early stages. An important purpose of PP is about getting legitimacy for public decisions and building support for plans among the public (Innes and Booher [4]).

\section{Methods of public participation}

At the end of this century two major changes has occurred in the legal orders of almost every country as well as in international law. First, human rights, and later, the environment were universally recognized as fundamental social values. Nowadays, there is a growing consensus that there is a new right which has a procedural character; it is PP which needs a legal framework. This category can contribute to the development not only as a practice but also as a theory of participation which help to adopt new innovative solutions in our communities (James and Blamey [5]).

\subsection{Theoretical basis}

The theoretical basis is addressed to improve PP in environmental decisions and is organized by reliance on human action, so its support and development help to upgrade the urban environment; hence the upgrading of human behaviours would support PP in environmental context (fig. 2). 
So, before people participate, the basic needs must be fulfilled to achieve self actualization in the psychological sense, which includes needs for understanding, aesthetic appreciation and purely spiritual needs (Osuji [6]).

Human needs start from physiological needs then safety needs and rise to belonging, esteem, knowledge, and aesthetic needs. Finally, the human will have a sense of self actualization (Osuji [6]).

\subsubsection{Behavioural upgrading}

A hierarchy of five levels of basic needs (Deficiency Needs) must be satisfied before an individual reaches self actualization. Beyond these needs, higher levels of needs exist (Growth Needs), which include needs for understanding, aesthetic appreciation and purely spiritual needs, fig.1.

A person's level of gratification is represented by a horizontal line across all needs, and growth would be represented by that horizontal line moving upwards through all needs (Osuji [6]).

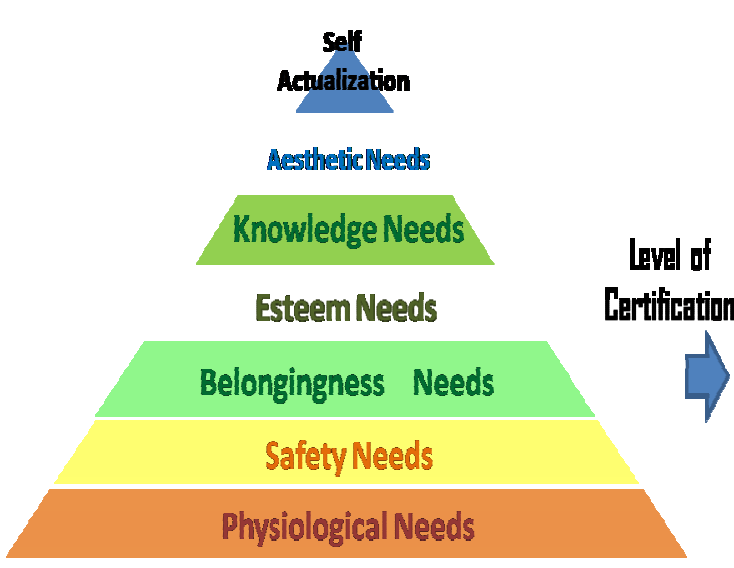

Hierarchy of Needs Diagram

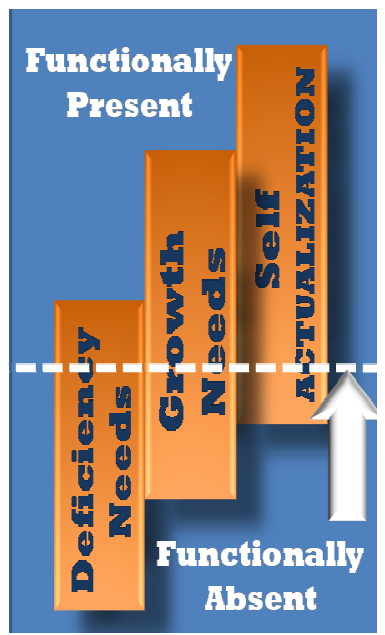

Figure 1: The hierarchy of needs. Functionally, the influence of citizens is absent if there are a deficiency of needs, it will be present if citizens get their necessary needs, from Osuji and after of the Maslovian diagram of Human Needs [6].

\subsubsection{Levels of participation}

Different levels of public participation allow different levels of public involvement in the decision-making process (Arnstein [7]). Generally, as the level of involvement increases the number of individuals involved decreases fig. 2.

\subsubsection{Building trust in Government}

The main issue now is: how government will build trust through public participation? In Egypt, people lost trust in governmental decisions and policy 


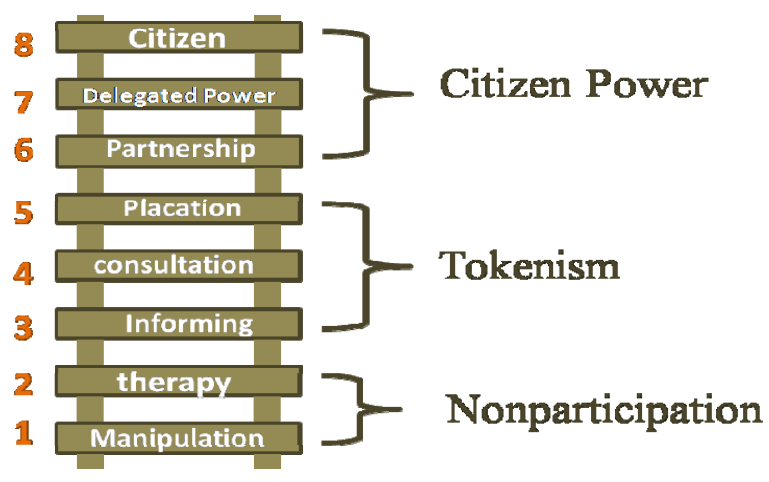

Figure 2: The Ladder of Participation, from Arnstein [7].

makers. Sustainability demands an even increasing trust to balance the social life; accordingly PP practice helps in rebuilding the lost trust between citizens and the government. If trust is lost, a long process of confirmatory experience will be required to rebuild it another time (Raimond [2]). To formulate the participation program with high level of trust, the following aspects should be considered: (a) Illustrate the needs; it must be sufficiently flexible and have a broad base to accommodate the full range of public concerns. (b) Assessing the content of the debate, this content may go beyond the broad issues of risk and impact. (c) Designing the PP process. This should explicitly recognize the levels of distrust that exist. (d) Designing the strategies and techniques. A variety of strategies will be necessary to reach the full spectrum of social groups.

\subsection{Dealing with public anger and aggressive behaviour}

Some developmental decisions that are taken by a group of policy makers and the governmental are confronted and are in conflict with some citizens, so such problem should be dealt with using the conflict theory:

Sandman's "Risk = Hazard + Outrage" (Raimond [2]).

To deal with this case, the groups should identify and explain general goals, have a good expectations and listening, help the groups to solve the fatal problems, and provide opportunity to follow up. There are some skills which are important to deal with anger, such as: assertiveness, listening, negotiation, productive criticism, praise, and confrontation (Raimond [2]).

\section{Designing public participation processes}

The guidance for the future is done by understanding the past, so designing the public participation process will be described into the following five steps, fig. 3 .

\subsection{Determine the need for public participation}

Three main items are determined for the PP processes: (1) Decision makers must have some flexibility and open mindedness regarding the nature of the 


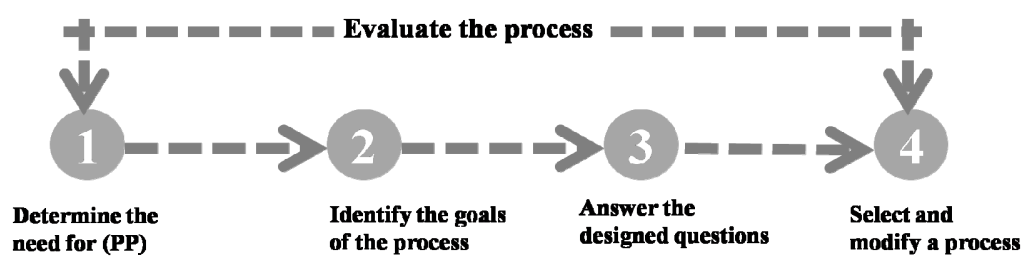

Figure 3: $\quad$ The diagram depicts the steps of PP process.

process and its outcomes; they must recognize the legitimacy of PP process and gain public trust. (2) The arguing is a substantive rationale, which makes PP lead to objectively superior decisions; as public may bring valuable information, deeper solutions, or creative estimation in a given problem.(3) Normative rationales for $\mathrm{PP}$ that it is both the right of citizens and it is the way for democracy and a more healthy society (Beierle and Cayford [1]).

\subsection{Identify the goals of the process}

The goals of PP process should be considered, the most important of this goals are the social goals, such as identifying the public value when the decision is making, increasing citizens' awareness to get them the ability to participate, and solving the conflicts to find the trust between citizens and governments. The barriers should be considered that make this goals difficult to be achieved, such as neglecting the degree of pre-existing conflict, or the loss of trust in an earlier issue, these conditions should be addressed and emphasized in the process (Beierle and Cayford [1]).

\subsection{Answer the designed questions}

Four design questions should be answered: (1) who should participate? The answer is; all citizens, especially the middle class who probably reflect the public values more accurately, and stakeholders who have a political influence to be that their input is heard and acted on. (2) What kind of engagement is appropriate? The answer is, the engagement between stakeholders and decision makers depends on participatory mechanism, shared information and deliberation methods. (3) How much influence should public have? The answer is, the level of public influence depends on the sequence and steps of PP process and given information needed to formulate the required recommendations. Planners must consider how much influences must be granted. (4) What role should government play? The answer is, the role of government is to make the balance act between responsiveness and control, as process becomes more intensive and participants take on greater responsibility in formulating recommendations (Beierle and Cayford [1]).

\subsection{Select and modify the process}

The design questions can be selected according to the scope of inclusion, representation, kind of engagement, level of public influence, and role of the government, table1. 
Table 1: The types of participation mechanism, the figure shows the modifying and selection of the PP process, from Beierle and Cayford [1].

\begin{tabular}{|c|c|c|c|c|c|c|c|c|c|c|}
\hline \multirow{2}{*}{ 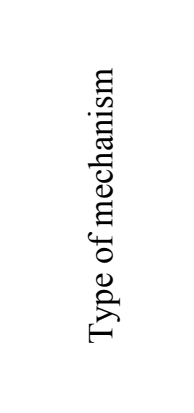 } & \multicolumn{2}{|c|}{ 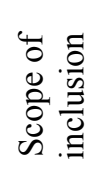 } & \multicolumn{2}{|c|}{ 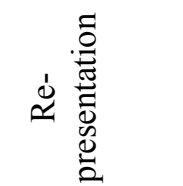 } & \multicolumn{2}{|c|}{ 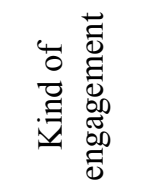 } & \multicolumn{2}{|c|}{ 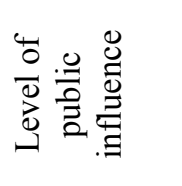 } & \multicolumn{2}{|c|}{$\begin{array}{ll} & \overrightarrow{0} \\
0 & 0 \\
0 & \Xi \\
0 & 0 \\
0 & 0 \\
0 & 0 \\
\simeq & 0 \\
& 0\end{array}$} \\
\hline & 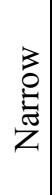 & 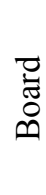 & $\begin{array}{ll} & 0 \\
. & 0 \\
0 & 0 \\
0 & 0 \\
\infty & 0 \\
& 0\end{array}$ & 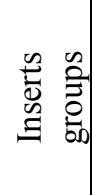 & 它 & 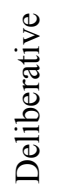 & 3. & 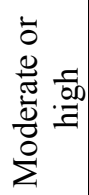 & 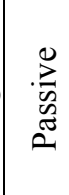 & : \\
\hline $\begin{array}{l}\text { Public } \\
\text { comments }\end{array}$ & & $x$ & $x$ & & $x$ & $x$ & & & & $x$ \\
\hline Surveys & & $x$ & $x$ & & $x$ & $x$ & & & & $x$ \\
\hline $\begin{array}{l}\text { Public } \\
\text { meeting and } \\
\text { hearing }\end{array}$ & & $x$ & 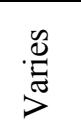 & 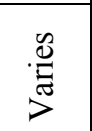 & $x$ & $x$ & & & & $x$ \\
\hline $\begin{array}{l}\text { Advisory } \\
\text { committees } \\
\text { not seeking } \\
\text { consensus }\end{array}$ & $\times$ & & 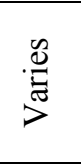 & 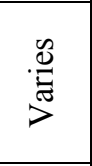 & 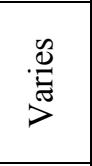 & $\stackrel{\mathscr{e}}{\frac{\mathscr{E}}{*}}$ & $\frac{n}{\pi}$ & $\cdot \frac{\mathscr{U}}{\tilde{\pi}}$ & 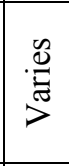 & 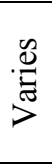 \\
\hline $\begin{array}{l}\text { Advisory } \\
\text { committees } \\
\text { seeking } \\
\text { consensus }\end{array}$ & $x$ & & & $x$ & & $x$ & & $x$ & 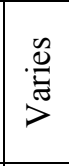 & $\frac{\mathscr{U}}{\stackrel{\Xi}{*}}$ \\
\hline $\begin{array}{l}\text { Citizens } \\
\text { juries }\end{array}$ & $x$ & & $x$ & & & $x$ & $x$ & & $x$ & \\
\hline $\begin{array}{l}\text { Negotiations } \\
\text { and } \\
\text { mediations }\end{array}$ & $x$ & & & $x$ & & $x$ & & $x$ & $x$ & \\
\hline
\end{tabular}

\subsection{Evaluate the process}

The evaluation helps planners to understand what the public and agencies accomplish and build as an information base to achieve PP with satisfactory results, fig. 4 .

\section{Public participation practice}

The fact that people who have no technical experience cannot be able to participate in decision making, therefore, over the last years the efforts had been 


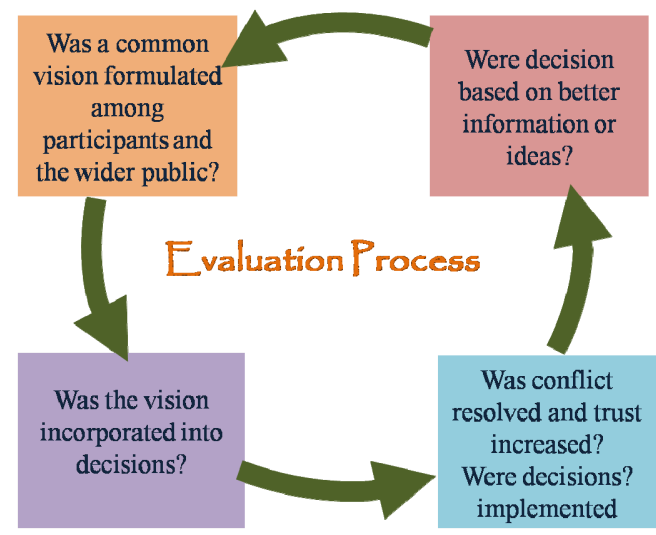

Figure 4: The diagram depicts the evaluation method of participation process, from Beierle and Cayford [1].

done to build up knowledge about the range of tools and methodologies, as well as expertise upon which these people can participate (EPA [8]\}.

\subsection{Guiding principles of successful public participation}

There are some guiding principles that should be respected before carrying out the PP process: (a) Early planning and publishing the details of the scheme which is requested to participate in. Then identify the sources of fund; (b) Fixing a place and a time to round up all participants, then assigning of the stakeholders and their legitimacy; (c) Choosing the appropriate techniques to be used for each stage of the process. (d) Allow sufficient time for stakeholders to assimilate and respond to information EPA [8]. Then ensure giving a feedback on all issues raised to people. (e) The technical complexity of some schemes may become an obstacle in the way of those voluntarily participating. To avoid that, the decision makers have to encourage dialogue, debate and collaboration, use effective communication media, and present simple and easily adapted proposals according to the progress of the continuous discussion (Miskowiak [9]).

\subsection{Examples of successful public participation Process}

\subsubsection{Development of Stuttgart railway station, Germany}

Project Description: Stuttgart Railway station is a particular case; the city lies in a valley and has a geographic cul-de-sac block as an extension for the city centre. The station is a terminus block and difficult to be linked to city center, the city center was missing the connection to the high-speed rail network that is being developed throughout Europe. The station was designed to be a "zero-energy station", fig. 5.

The old station will be at the top of the new subterranean tracks and platforms; station hall is illuminated by natural light that will fall into the space 


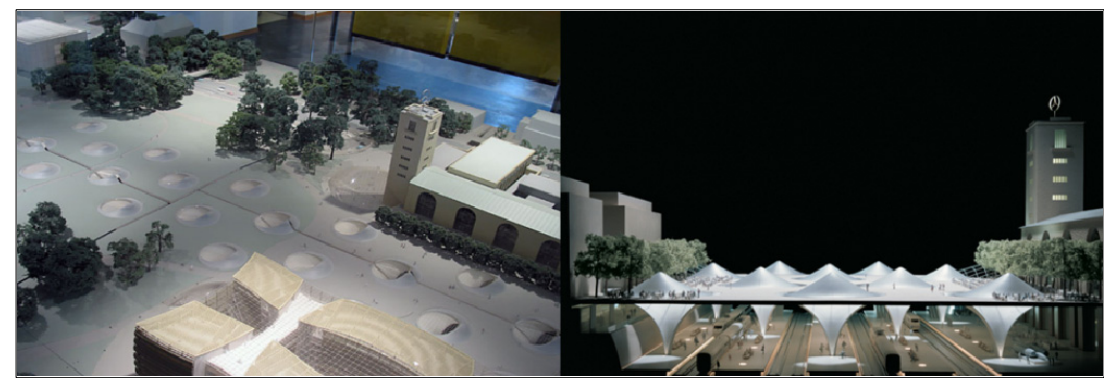

Figure 5: The proposal conserves the heritage of old building of the station, the model of the project is put inside to offer the chance for all participants to involve, from Hadergasser et al. [10].

through large circular shapes. The new station will give Stuttgart a new centre, and integrate the historic fabric into the new design. The historic building and the new station link the old and new sections of the city (Hadergasser et al. [10]).

Public Participation during the complete process: During the first preliminary studies of the project by the client and the planners, the public, the political committees and the institutional lobbies were incorporated into the planning and approval procedures for Stuttgart main station (Hadergasser et al. [10]).

A public information centre at the main station has been opened over 10 years ago. The permanent exhibition extends over three levels, showing the newest plans and models forth building project. The approval procedure takes place in several stages. Institutional lobbies and political committees, additionally receive information on an ongoing basis throughout planning to enable their suggestions or doubts to flow directly into the planning process (Hadergasser et al. [10]).

\subsubsection{The prevention of Itami airport and the construction scenario of a new airport in Kansai, Japan}

This example is relevant to caring about Public Anger and Aggressive Behaviour, in the mid of 1980s Osaka's Itami Airport was insufficient for the needs of the Kansai region in Japan. When the authorities found a land site for a new airport, they learned from the last experience of Tokyo in building the Narita Airport. the narrative were that the protests of the farmers whom were forced to sale their land, they refused to move, the authorities did not care about the aggressive Behaviour, a substantial group of violent radical activists in Japan flock to a public protest, they coherent to prevent the construction of the Narita Airport, they bombed fire on the site equipment, there were several deaths in the Narita Airport protests and three thousand radical activists were arrested (Applet-magic [11]).

When work started in Kansai airport, the authorities headed off a potential protest from Osaka Bay fishermen who would have their livelihood disturbed by the construction, payment was offered by the airport authorities and accepted by the fishermen, consequently the project had been constructed (Appletmagic [11]). 


\section{Implementation of public participation in Egypt}

\subsection{Current situation in Egypt}

In Egypt, PP is never been adopted in urban development projects, the only case where PP was processed in 1950s for national liberation (Halim [12]).

The absence of PP is due to socioeconomic, cultural poverty and centralization of decision making. These barriers always strut the progress of PP, and to overcome these barriers democracy should be activated in the public life, citizens will be encouraged to participate in decision making and their awareness will be increased (Halim [12]).

\subsection{Implementation of PP through a model: "The development project of Sidi Gaber railway station, Alexandria, Egypt"}

\subsubsection{Justification for selecting the case study}

Alexandria is the oldest city in Egypt and it is a great city in between the cities surrounding, the Mediterranean coast was the beginning of the old world and the origin of the present civilization, fig. 6 .
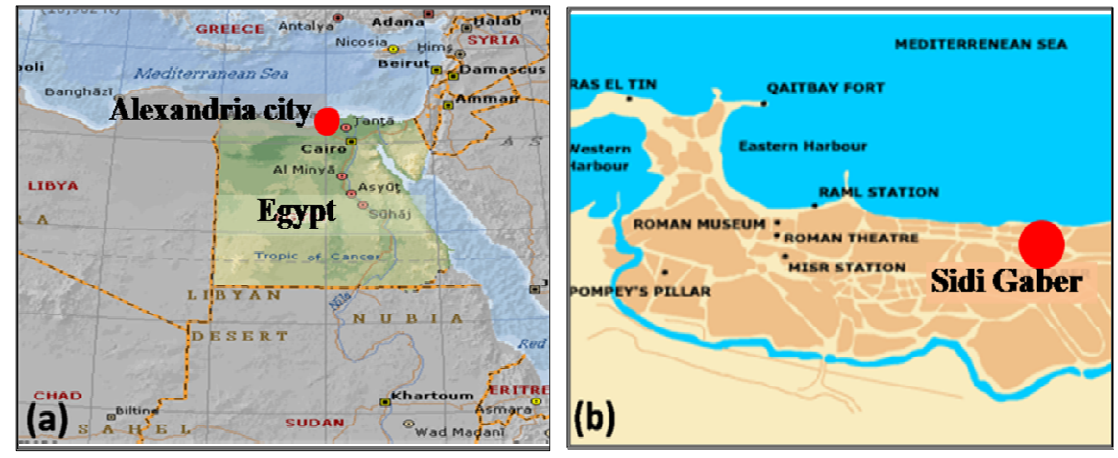

Figure 6: The map of Egypt in figure (a), and map of Alexandria in figure (b), from World Atlas.

Hence the study of its civilized formation and how it has grown, is considered the start point to know its present problems and how to think about their solutions, how to have the development without any destruction of the ancient and valuable buildings taking in to consideration the future requirements that influence the random development.

Sidi Gaber railway station is one of oldest Egyptian stations; it was the first railway lines that constructed outside Europe. In 1850, "Khedive Abass" was signed with the British designer "Robert Stifnson" to construct railway line between Cairo and Alexandria that costs $£ 65,000$ for 209 kilometer in length [4].

Historically, Sidi Gaber is the station of memories, in the twentieth century it welcomed the return of leader "Saad Zaghlol" after his expatriation (fig. 7). 

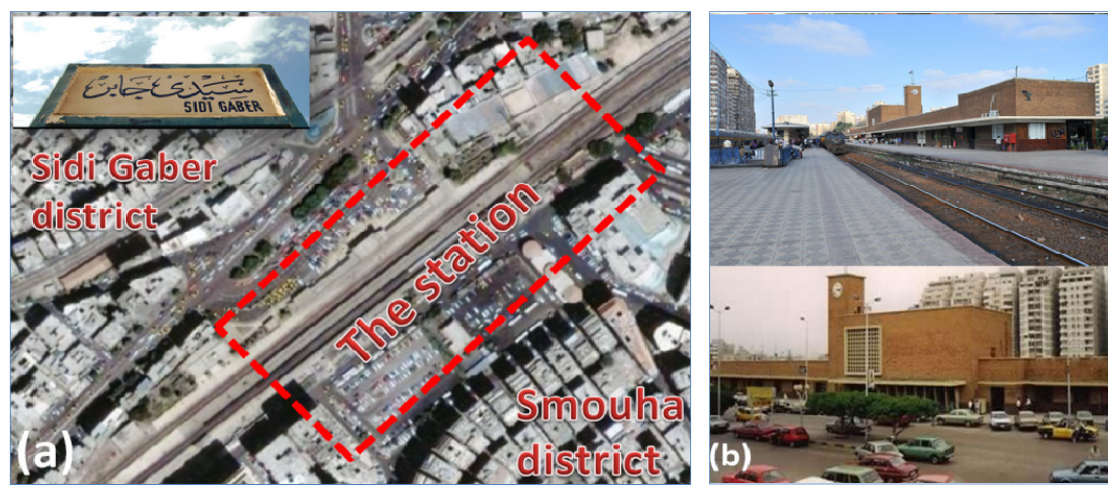

Figure 7: Map in figure (a) depicts the location of Sidi Gaber railway station between Sidi Gaber district and Smouha district; photos in figure (b) show the station building.

\subsubsection{The current project description}

The new project of Sidi Gaber station will consists of two floors to be constructed above the existing railway lines; it will be a commercial and recreational uses. The development project will not be concerned about the area problems, or to modify the urban fabric in order to avoid the traffic problems, and the conflicts between pedestrians and vehicles.

\subsubsection{Identification of main issues}

Identifying issues of concern should be done in early consultation and survey procedures, Issues and aspects of interests are prioritized as follows: (1) Resolving traffic problems; (2) Improving the visual quality; (3) Creating safety walkable areas, transition movements, and urban spaces; (4) Improving the connection between Smoha district and Sidi Gaber district; (5) Linking Sidi Gaber coast to the station increase activities; (6) Improving infrastructure services; (7) Creating new traffic routes; (8) Increasing parking facilities; (9) Increasing the awareness of PP; (10) Future redevelopment study plan for the area for long terms.

\subsubsection{Program design and strategies}

- Identifying Stakeholders: Key stakeholder survey and analysis is to be carried out to identify various groups of stakeholders, as well as to assess their relativity and influence on the project;

- Governmental agencies: The Comprehensive Plan Administration, The ministry of transportation, The Regional Authority for Tourism Promotion, ecological ministries, Community Council, Local Administration of Chark Region, Administration of Urban Planning, Traffic, and Housing administrations;

- Directly affected groups: Architects, Travellers, Residents, and Shopkeepers;

- Indirectly affected groups: Shoppers, Pedestrians and Drivers;

- Private sector developers: Landlords, Shop owners and Investors. 


\subsubsection{Formulating the program}

An approach to the range of techniques that suit citizens and characteristics of district including interviews and workshops, the following phases will constitute the public participation program: (1) Structured interviews: Interviewing various community members to identify the roles and range of interests and issues that are crucial to the development of the station in their perception; (2) Strategic plan formation: Participants, in small groups, are given the list of identified goals from which they select four statements that seems important in developing the area; (3) The project scheme should be presented with worksheets about the model cycle phases to inquire citizen advisory opinion; (4) Particularly, in Sidi Gaber area, the nature of population and the level of their assimilation will accept modern techniques in participation processes such as media or web sites methods. They have enough sensibility, so the process will not have any conflicts, but the groups should have equanimity of mind and cool of reaction.

\subsubsection{Creating dialogue}

To allow community members to visualize the impact of the designed proposal of the project, graphic materials are to be used as the basis for comparing proposed developments to the existing settings. Explicit criteria are presented to the public as a series of indicators, these indicators are organized in different categories and presented in a visual format and the public opinion on different intervention strategies will have its input into the project modification.

Preferences and Outcomes: The aim is to develop a consistent set of criteria by assessing the preferences of participants. The relevant example of Stuttgart railway station, Germany can help to constitute the basis of appraisal criteria to be applied regionally in order to achieve such goal, the dialogue needs to be recorded under the following headings: (1) Visual representation of the station site; (2) Representation of its Heritage conservation status; (3) Representation of possible management or development alternatives; (4) Recording the public perception of aesthetic and symbolic values of the station can give at future management options; (5) Clear Public preferences for alternative management options for the site, as proposed by Alexandria City Planning. (6) A selection of efficient participation tools that have been practically experienced. (7) Collecting and building of a public preferences database as the baseline information.

\section{The model}

At the end of preliminary studies of project, the researcher hypothesized putting the model of the project inside the old station for showing it to all citizens; they should fill the response sheet with their opinion about this project by answering some questions that will ease the process for them. The response sheet will include the drawings of the project, fig. 8 .

The construction of the new building will in the form of a steel structure above the station platform, the trains will moving down,the project consists of three levels of commercial shops, cafeterias, and stations' offices, fig. 9. 


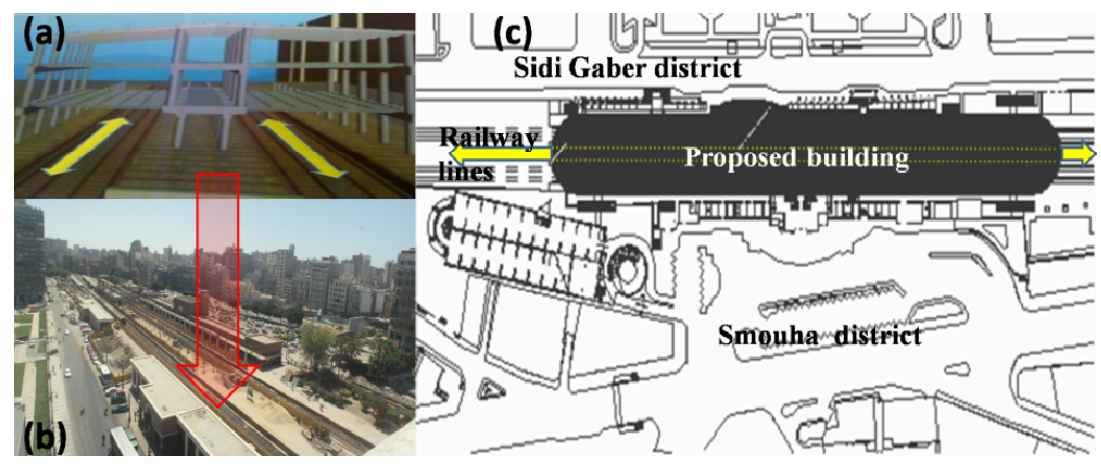

Figure 8: Steel frames shown in figure (a), site of new building shown in figure (b), plan of new building above the railway lines shown in figure (c).
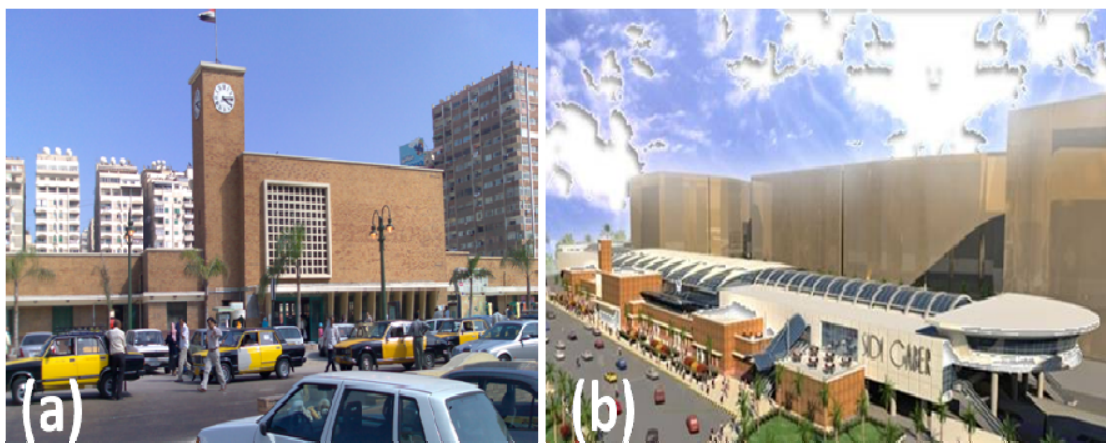

Figure 9: The station before the new project appears in figure (a), the station perspective after construction of the new building appears in figure (b), it consists of three levels of commercial uses.

\subsection{The project evaluation according to the response of affected groups}

The questionnaire sample was fifty members of concerned people (40 travellers, and 10 architects); following questions were answered in the response sheets that were delivered with the work sheets of drawings, table 2 explains their response about the development project of Sidi Gaber.

The final results of the questionnaire about Sidi Gaber project will be more clear in the following charts, this will be as a guide for the decision makers to know what the citizens need to improve in their life, and to get their rights in planning their communities, fig. 10 .

The decision makers should modify the proposal to meet the citizens' needs and apply the environmental democracy in their decisions. 
Table 2: The response of the affected group through the sample of participants.

\begin{tabular}{|l|c|c|c|}
\hline \multicolumn{1}{|c|}{ Question } & \multicolumn{3}{|c|}{ Answers } \\
\cline { 2 - 4 } & Yes & No & Maybe \\
\hline $\begin{array}{l}\text { 1. Were you invited before to participate in the } \\
\text { development project of Sidi Gaber Railway } \\
\text { Station? }\end{array}$ & 0 & 50 & 0 \\
\hline $\begin{array}{l}\text { 2. Do you agree that Sidi Gaber railway station } \\
\text { and the context of adjacent area are in need of } \\
\text { development? }\end{array}$ & 35 & 5 & 10 \\
\hline $\begin{array}{l}\text { 3. In your opinion, are traffic problems the } \\
\text { important issues that need addressing in this area? }\end{array}$ & 40 & 3 & 7 \\
\hline $\begin{array}{l}\text { 4. What is your personal thought about the final } \\
\text { proposal of Sidi Gaber, will it be suitable and } \\
\text { harmonic with the old building character? }\end{array}$ & 6 & 35 & 9 \\
\hline $\begin{array}{l}\text { 5. In your mind, do you expect that the project } \\
\text { will find solutions for the present problems? }\end{array}$ & 8 & 37 & 5 \\
\hline
\end{tabular}

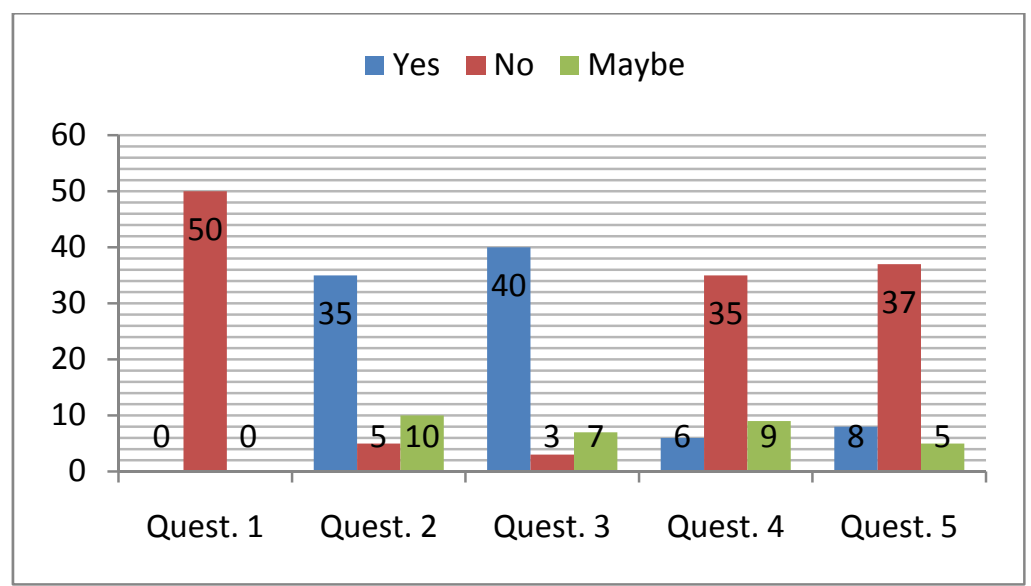

Figure 10: Final results of inserts groups reflecting their decision about the Sidi Gaber development project.

\section{Conclusion}

PP is most efficient in empowering local communities to promote the liveability of their environment, maintain their heritage, and at the same time promoting the quality of life, economic development, and social equity. PP should be applied in early stage, in all levels by using diverse methods. The implementation of the PP 
process in Egypt still needs to change the policy from centralization to democracy, not only in holding the decision, but also in the different range of social and political life. Decision makers should be from the specialists whom are able to decide the right decision; they should give the chance to people to participate.

A review of participation methods and techniques showed that awareness and commitment of both the stakeholders and the official bodies is the key for the success of any participatory action. It helps to build up trust and respect to build up in the relationship between official and non-official agencies, it also provide access to local groups in relative decision making. The present legislation and bureaucracy, as well as the cultural, economical and political settings restricts introducing public participation on the national level, which is likely to leave the stakeholders with feelings of frustration and alienation.

\section{Recommendations}

For advancing and improving PP in sustainable development projects the last experiences should be summarized and collected. General principles are formulated and followed by some recommendations to define few basic tasks for participants to participate, these recommendations are:

Politicians should: (1) Encourage the creation of civic and institutional cultures that recognize public involvement as a fundamental and main component of any democratic system; (2) Incorporate effective public involvement laws, rules and practices at every level of decision making; (3) Create a supportive legal and regulatory framework that will guarantee the process of shaping the decisions that affect their lives; (4) Assume an obligation to communicate with the public on what was decided and why one course of action was preferred over alternatives.

Local government officials should: (1) Develop and implement strategies to reinforce the democratic principles of individual rights and responsibilities for all "stakeholders" of society; (2) Adopt requirements that project budgets should include resources for information and participation; (3) Adopt and implement communication strategies based on public needs rather than on institutional professional preferences.

NGOs should: Work to develop cross sectored coalitions of NGOs and interest groups to promote political, institutional and general societal benefits which move to better informed and more actively engaged public.

National governments should: Make PP a pre-requisite for funding local initiatives; Incorporate public participation requirements into the national legal system.

The private sector should: Begin discussions with the government regarding expectations for corporate responsibility with respect to better public information and greater public involvement. 


\section{References}

[1] Beierle. T. B. \& Cayford. Democracy in Practice, Resources for the future, RFF PRESS, 2002

[2] Raimond R. R., Trust and Conflict in Public Participation, Division of Hazardous Materials and Waste Management. Colorado Department of Public Health and Environment, Jan. 2001

[3] Asharq Al-Awsat, Newspaper No 11008 January 2009. Sidi Gaber the Station of Memories [Web Page]. Accessed 2010 Apr 25. Available at: http://www.aawsat.com/details.asp?section $=54 \&$ article $=503172 \&$ issueno $=$ 11008

[4] Innes. J. E. \& Booher. D. E., Public Participation in Planning, New Strategies for the 21st Century. Prepared to Annual Conference of the Association of Collegiate Schools of Planning, University of California at Berkeley, Nov. 2000

[5] Rosemary F James \& Russell K Blamey. Manual on Public Participation in Environmental Decision-making, Rhetoric to Reality, Brisbane, Australia: International Symposium on Society and Resource Management, Jul.1999

[6] Osuji S. N., Maslovian Theory of Human Needs, Implications for Adult Education Curriculum in Nigeria. Essays in Education, Obafemi Awolowo University, 2007

[7] Arnstein S. R., A ladder of citizen participation, Journal of the Royal Town Planning Institute, Apr.1971

[8] EPA, Public Participation and Accountability Workgroup of the National Environmental Justice Advisory Council A Federal Advisory Committee to the U.S., The Model Plan for Public Participation, Office of Environmental Justice. USA, Feb.2000

[9] Miskowiak D., Crafting an Effective Plan for Public Participation, Center for Land Use Education. USA; Nov.2004

[10] Hadergasser H., Penn S. \& Alexander May, The 'Stuttgart 21' Synergy Concept. LACER No. 2, 1997

[11] Applet-magic.com. The Construction of Kansai Airport, [Web Page] Accessed 2008 May. Available at: http://www.sjsu.edu/faculty/watkins/ kansaiairport.htm

[12] Halim A. A., Supporting Public Participation in Egypt. Al Ahram Regional Press Institute; 2005 Feb 22 